\title{
DESENVOLVIMENTO DE UM JOGO DE TABULEIRO COM CARACTERÍSTICAS DO XADREZ
}

\section{DEVELOPMENT OF A BOARD GAME WITH CHESS CHARACTERISTICS}

\author{
Mauricio Salomon ${ }^{1}$, Graduando \\ André Schlemmer ${ }^{2}$, M.Sc. \\ (1) Universidade do Contestado - Campus Rio Negrinho \\ e-mail:mauricio-salomon@hotmail.com \\ (2) Universidade do Contestado - Campus Rio Negrinho \\ e-mail:schlemmer.andre@gmail.com
}

Design de jogos, Xadrez, Inovação

\begin{abstract}
Das características do xadrez e da ascensão do mercado de jogos projetamos um novo jogo de tabuleiro. Por intermédio de uma metodologia adaptada o jogo proporcionou jogabilidade clara e simples. Além de mecanismos e peças diferenciadas, o jogo trouxe inovação em seu formato e na personalização estética, diferenciando jogadas e ações estratégicas, surgindo assim uma nova opção para o mercado.
\end{abstract}

Game design, Chess, Innovation

From characteristics of chess and rise of the gaming market, we design a new board game. Through of adapted methodology the game provided clear and simple gameplay. Besides to different mechanisms and pieces, the game brought innovation in its format and aesthetic customization, differentiating moves and strategic actions, thus creating a new option for the market.

\section{Introdução}

Além do aspecto mercadológico, jogos são ferramentas de entretenimento muito presentes na vida de crianças e adultos, sendo eletrônicos, esportivos, de tabuleiro, etc. Sua importância é facilmente percebida pela maneira que está difundido nas escolas, de forma didática e interativa (práticas lúdicas), e também, entre famílias e grupos de amigos, que buscam em jogos de tabuleiro uma forma de se reunirem por diversão e lazer (FIANI, 2006).

Dentre os jogos de tabuleiro, um dos que recebe destaque é o xadrez, sua prática está registrada com mais de dez mil anos de história e evolução, passada de cultura a cultura até a sociedade contemporânea. Sua importância e valor podem ser percebidos pela forma que está difundido na sociedade e pela existência de campeonatos mundiais a mais de 100 anos (MARCELO \& PESCUITE, 2009). 


\section{$16^{\circ}$ \\ ERGODESIGN USIHC CINAHPA}

Portanto, propomos por intermédio do jogo de xadrez encontrar as mecânicas de jogabilidade mais intuitivas e conhecidas pelos usuários e através de um processo de desenvolvimento de jogos inovar e projetar um jogo com regras simples, com objetivos e jogabilidade clara, criando um apelo estético diferenciado e que sirva como meio de lazer e entretenimento para os jogadores.

\section{Xadrez}

O xadrez é um jogo competitivo que cria desafios intelectuais entre os jogadores, extraindo o máximo de criatividade e técnica em cada partida. Porém, possui um enorme potencial como um jogo didático de valor pedagógico, pois estimula o desenvolvimento de crianças e adolescentes na fase escolar (MANZANO \& VILA, 2002).

Outra característica que torna o xadrez um jogo peculiar, é a possibilidade de registro das partidas e reproduções destas. A partir disso, a medida que o acervo de possibilidades de jogadas aumenta, o jogo se torna uma fonte de aprendizagem (CASTRO, 1994).

O jogo de xadrez sofreu mudanças significativas por volta de 1475 , tais mudanças alteraram as regras do xadrez árabe, e deram origem ao jogo da Europa Ocidental. Basicamente, algumas peças foram substituídas e o ritmo do jogo acelerado. $\mathrm{Na}$ segunda metade do século XVI, o xadrez teve seu grande desenvolvimento, e os melhores jogadores passaram a ser patrocinados por parte da burguesia, incluindo os reis da época, com essas mudanças se estabeleceu um mecanismo padrão e que permaneceu neste formato até os dias atuais (CASTRO, 1994).

Com as referências do Xadrez, encontramos informações que colaboram diretamente para o ensino-aprendizagem, que segundo Doubek (19821, p. 89) gera "uma capacidade de enxergar e de prever, de abranger uma partida em sua totalidade, de escolher entre muitas possibilidades imagináveis qual é a melhor, de pacientemente buscar soluções em circunstâncias adversas". $16^{\circ}$ Ergodesign - Congresso Internacional de Ergonomia e Usabilidade de Interfaces Humano Tecnológica: Produto, Informações Ambientes Construídos e Transporte

$16^{\circ}$ USIHC - Congresso Internacional de Ergonomia e Usabilidade de Interfaces Humano Computador

CINAHPA | 2017 - Congresso Internacional de Ambientes Hipermídia para Aprendizagem.

Loureiro (2006) cita projetos em que o Xadrez colabora na formação intelectual e autodisciplinar dos alunos, além disso, o jogo proporciona o desenvolvimento de habilidades como raciocínio lógico, estratégico e matemático, capacidade de concentração, habilidades de observação, reflexão e análise, hábitos necessários a tomada de decisões, criatividade e imaginação.

\subsection{Mecanismos}

Jogado em um tabuleiro de 64 casas, cada jogador tem inicialmente 16 peças de 6 tipos distintos, cada qual com sua respectiva importância, movimentos e possibilidades de captura específicos (CASTRO, 1994).

Por curiosidade, apenas os quatro primeiros lances podem produzir cerca de 70 mil diferentes posições. Trata-se, portanto, de um jogo de possibilidades e estratégia (CASTRO, 1994).

O tabuleiro é o ambiente para o movimento das peças, fornece dois tipos de movimentos base, em linhas retas horizontais ou verticais, e também, em diagonais. A única peça do jogo que não segue o padrão de movimento citado acima, seguindo apenas a contagem de casas no tabuleiro é o cavalo. A quantidade de casas à serem percorridas variam de acordo com a peça (MANZANO \& VILA, 2002).

As mecânicas de ataque no xadrez são fundamentais para o desenvolvimento da partida e o cumprimento do objetivo, caracterizado pelo xeque mate. Para realizar um ataque, o jogador deve levar a sua peça até a casa da peça inimiga, retirando assim a peça do adversário e assumindo a posição da peça atacada. Essa mecânica ocorre da mesma maneira para todas as peças ou situações, todavia, os limites de movimento da peça que está atacando devem ser respeitados conforme a natureza de cada peça utilizada durante a jogada (MANZANO \& VILA, 2002).

As características do mecanismo de jogabilidade do xadrez são essências para um novo projeto de jogo de tabuleiro, como exemplo, o método de capturar peças, os movimentos pelo tabuleiro, as
Realização:

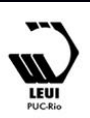




\section{$16^{\circ}$ \\ ERGODESIGN USIHC CINAHPA}

relações de poder exercidas entre as peças, que influencia diretamente no objetivo do jogo, como é o caso da captura do rei. Por isso, consideramos essas características como aspectos fundamentais no desenvolvimento de um novo jogo de tabuleiro que vise adaptabilidade rápida e familiaridade dos usuários com o jogo do xadrez.

\section{Design de Jogos}

Segundo Marcelo e Pescuite (2009), projetar um jogo não é uma tarefa fácil. Combinar os elementos que formam um sistema para que possa cumprir sua tarefa de maneira almejada é uma questão que requer qualidades encontradas em poucos indivíduos.

Assim, o designer de jogos é o indivíduo que visualiza um jogo em uma situação real, desenvolve as regras, estabelece objetivos, os processos necessários para atingir os objetivos, cria o universo, a mecânica do jogo e desenvolve toda a estruturação pela qual os jogadores ficarão envolvidos.

Os jogos são sistemas frágeis, sendo que qualquer perturbação que possa ocorrer nas ligações que o compõem, pode resultar no desmoronamento do sistema como um todo (SALEN e ZIMMERMAN, 2004).

Sendo assim, há algumas etapas que devem ser seguidas para a formulação de um jogo, independente da sua abordagem. O processo inicia a partir da ideia do tema, onde são definidos os conceitos visuais e funcionais que devem inspirar todo o desenvolvimento e decorrer do jogo, ou seja, desde o desenho das peças até o ambiente, tabuleiro ou cenário (MARCELO E PESCUITE, 2009).

Após a ideação da temática, é realizada a escolha das mecânicas (por exemplo, cartas, dados, peças), que serão utilizadas e que vão proporcionar a função principal de jogabilidade, que por sua vez será explorada pelos jogadores. Nesta etapa devem ser realizados testes mentais e comparativos a jogos que já possuam a mecânica para entender seu real impacto no jogo (MARCELO E PESCUITE, $16^{\circ}$ Ergodesign - Congresso Internacional de Ergonomia e Usabilidade de Interfaces Humano Tecnológica: Produto, Informações Ambientes Construídos e Transporte

$16^{\circ}$ USIHC - Congresso Internacional de Ergonomia e Usabilidade de Interfaces Humano Computador

CINAHPA | 2017 - Congresso Internacional de Ambientes Hipermídia para Aprendizagem.

2009).

Na fase de prototipagem é determina a produção física do jogo, primeiramente através de um modelo de baixo custo para a realização da fase de testes, e logo após o modelo final, com todas as características reais e funcionais do jogo projetado (MARCELO E PESCUITE, 2009).

Não é somente destas fases apresentadas até o momento que compõem o desenvolvimento do design de um jogo, a jogabilidade é um fator decisivo para cativar os usuários. Para Arruda (2014, p. 16) a "jogabilidade é a maneira como o jogo é elaborado para manter o desafio ao jogador. Jogos muito fáceis ou muito difíceis podem ser abandonados rapidamente, por não serem considerados divertidos ou não oferecerem possibilidades de aprendizagem do jogo".

Segundo Chandler (2009), a jogabilidade deve ser analisada desde os protótipos iniciais do jogo, com baixo custo de investimento, até os protótipos mais polidos, pois assim é possível captar a experiência que o jogador tem no decorrer da partida.

Essa experiência é importante, pois considera aspectos afirmados por Marcelo e Pescuite (2009), como duração da partida, diversão durante o jogo, clareza das regras e a fluidez que o jogo se desenvolve.

Além disso, a jogabilidade também é responsável pelos objetivos do jogo, fator que determina a satisfação e motiva o jogador a concluir a partida (LEITE \& MENDONÇA, 2013).

\section{Material e Métodos}

A metodologia escolhida para o projeto foi baseada em Sato (2010), que fundamentada nos princípios do game design. As três etapas fundamentais para o desenvolvimento de um jogo com os elementos e mecânicas essenciais são: (1) conceituação, (2) desenvolvimento e (3) implementação.

Além da metodologia base, foram utilizadas algumas adaptações baseadas em Marcelo e Pescuite (2009), que através de um estudo direto
Realização:

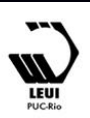




\section{$16^{\circ}$ \\ ERGODESIGN USIHC CINAHPA}

$16^{\circ}$ Ergodesign - Congresso Internacional de Ergonomia e Usabilidade de Interfaces Humano Tecnológica: Produto, Informações Ambientes Construídos e Transporte

$16^{\circ}$ USIHC - Congresso Internacional de Ergonomia e Usabilidade de Interfaces Humano Computador

CINAHPA | 2017 - Congresso Internacional de Ambientes Hipermídia para Aprendizagem. com jogos de tabuleiro, auxiliaram na inclusão das etapas: (1) escolha de mecânicas, (2) testes de jogabilidade e (3) avaliação final do produto, atuando em pontos estratégicos da metodologia de Sato (2010).

Para concretizas as etapas da metodologia adaptada de Sato (2010) e Marcelo e Pescuite (2009) utilizamos um briefing para obter informações importantes sobre a base inicial do projeto, bem como, possibilidades e limitações que devem ser obedecidas no desenvolvimento do jogo.

Na etapa da conceituação, inicia o desenvolvimento de ideias de conceito para o jogo, que envolve a temática principal, formas das peças, ambiente ou mecânicas de movimentação e interação. As ideias geradas nessa etapa devem ser submetidas a testes mentais de funcionalidade básica do jogo.

Os testes de experimentação devem ser realizados na fase posterior, a partir de protótipos de baixa fidelidade, normalmente produzidos em papel ou EVA, assim possibilitando uma maior liberdade nos testes e menos tempo gasto na confecção destes protótipos iniciais (SATO, 2010).

A definição de mecânicas é uma das partes essências para o êxito na obtenção de resultados com o jogo. É necessário determinar o tipo de elementos envolvidos, como dados, cartas e peças, como também as ações e reações que devem ser inseridas durante a partida do jogo (MARCELO \& PESCUITE, 2009).

A fase de testes acontece simultaneamente à fase de desenvolvimento, onde os protótipos de baixo custo devem ser postos à diversos tipos de testes básicos, para verificar a jogabilidade e pontos essenciais do jogo, como fluidez e clareza de regras. Também é necessário aperfeiçoar as regras e aprimorar pontos de mecânicas fundamentais, como movimentação pelo jogo, mecânicas de ataque ou defesa. Esta fase é realizada apenas pelo desenvolvedor, pois o projeto ainda não possui uma base sólida para testes com o usuário.

Na fase de implementação é necessário estabelecer um relacionamento entre o público e o protótipo final, para execução dos testes que serão utilizados na fase de avaliação. Devem ser escolhidos públicos em diversos níveis de conhecimento quanto há jogos de tabuleiro, para verificar importantes índices, como por exemplo, a clareza das regras, importantíssima para manter o jogo acessível.

Após os testes de implementação, deve ser aplicado questionários aos usuários para verificar os índices de clareza, fluidez, duração, diversão e estética, proporcionadas pelo protótipo final.

No caso de algum dos índices apresentar uma avaliação irregular ou baixa, o item deve ser analisado para possíveis correções nas etapas anteriores ou redesign.

\section{Resultados e Discussões}

O briefing organizado em forma de painel, considerou questões relativas ao jogo, como a temática, insights sobre mecânicas, e também, questões referentes à persona.

Estas personas, são de extrema importância para o desenvolvimento do projeto, por nortearem diversas características e exigências que o produto final deve apresentar. A persona definida foi baseada no público nerd/geek, com faixa etária de 16 a 27 anos, que utiliza jogos digitais online como meio de lazer e entretenimento. Este indivíduo gosta de se relacionar com seus amigos em jogos e é uma pessoa extremamente interessada em inovações.

Durante a conceituação foram criados rascunhos de ideias e insights para gerar a maior quantidade possível de alternativas para o tabuleiro e os elementos do jogo, aumentando o campo de escolha. Na figura 01, representamos parte dos rascunhos referentes aos modelos a serem utilizados no jogo.
Realização:

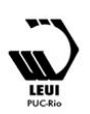


$16^{\circ}$ USIHC - Congresso Internacional de Ergonomia e Usabilidade de Interfaces Humano Computador

CINAHPA | 2017 - Congresso Internacional de Ambientes Hipermídia para Aprendizagem.

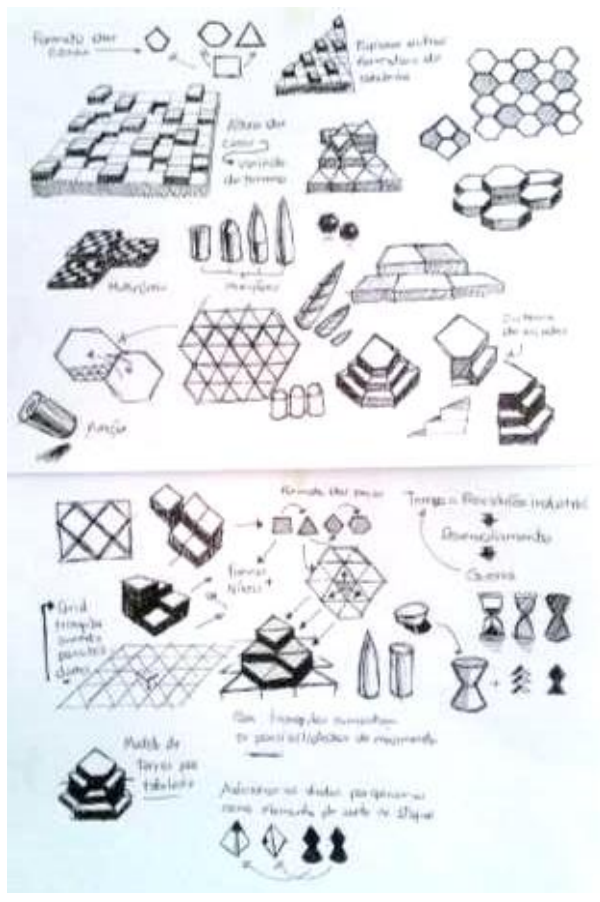

Figura 01: Ideias de modelos

Diante dos modelos criados, nossa escolha foi o tabuleiro hexagonal que fundamenta na possibilidade e flexibilidade que os seis lados oferecem ao encaixe de vários tabuleiros, facilitando assim a interação multijogador no ambiente de jogo.

A opção definida para o projeto, permite que as casas triangulares, internas ao tabuleiro, se derivam da utilização do número três como alternativa de prova real, onde a terceira possibilidade define uma probabilidade, além da escolha de duas direções, a terceira adiciona um cenário de incerteza, ou seja, adiciona características estratégicas ao jogo.

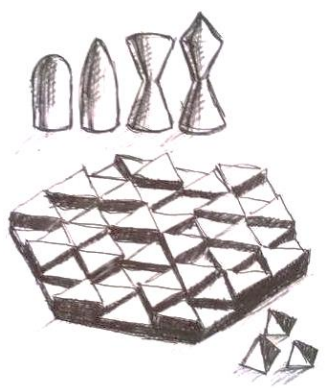

Figura 02: Alternativa escolhida
Após as verificações básicas da alternativa refinada no rascunho, com o briefing inicial, partimos para a etapa de desenvolvimento do protótipo real do produto, com as características definidas nos esquemas gerados. Esse rascunho ainda não garante a fidelidade, pois podem ser encontradas falhas na etapa de desenvolvimento, que não necessariamente voltam a etapa de conceituação para serem resolvidas.

A etapa de desenvolvimento visa a criação principal de dois protótipos, um de baixo e outro de alto investimento de recursos e materiais. Inicialmente desenvolvemos um protótipo com recursos reduzidos, utilizando materiais de baixo custo, como isopor e massa de modelar, para compor à fase de testes e facilitar a aplicação de melhorias.

Os testes foram realizados simulando todos os componentes do jogo, sendo o tabuleiro em níveis, as peças diferenciadas e suas funções específicas, e também, os dados de ataque. Para a realização dos testes com o protótipo foram consideradas as regras e mecânicas desenvolvidas, os testes foram aplicados com usuários aleatórios oriundos da Universidade do Contestado, do curso de Design.

Em relação ao protótipo final, na produção do tabuleiro foi utilizado o corte em MDF, pelo custo da matéria prima e do método de corte a laser serem relativamente baixos em contrapartida aos outros meios produtivos.

O processo se iniciou na separação do tabuleiro em duas peças: (A) base hexagonal e (B) casas triangulares, que foram enviadas para o corte. Após a conclusão do corte das peças, foi utilizado cola especial para MDF, de rápida secagem, que garante a precisão no posicionamento da sobreposição das casas sobre a base. O processo pode ser visualizado a seguir, na figura 03 .
Realização:
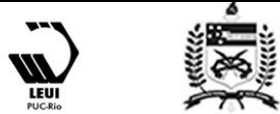


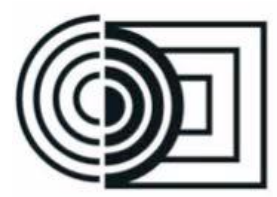

$16^{\circ}$ Ergodesign - Congresso Internacional de Ergonomia e Usabilidade de Interfaces Humano Tecnológica: Produto, Informações Ambientes Construídos e Transporte

$16^{\circ}$ USIHC - Congresso Internacional de Ergonomia e Usabilidade de Interfaces Humano Computador

CINAHPA | 2017 - Congresso Internacional de Ambientes Hipermídia para Aprendizagem.

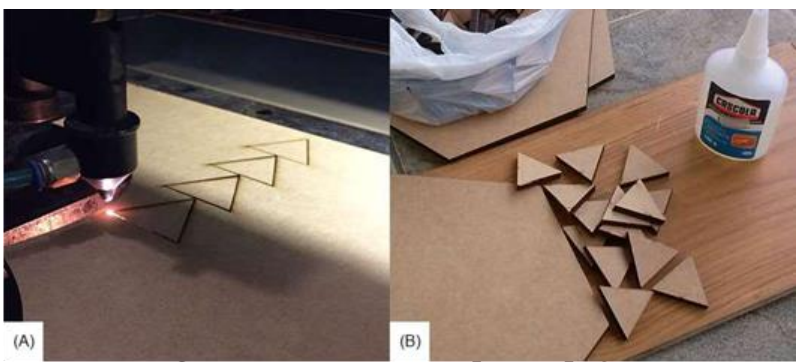

Para o acabamento, o tabuleiro foi submetido ao processo de pintura em laca, que proporciona a qualidade necessária ao produto mantendo suas faces e arestas lisas com cantos levemente arredondados. A laca é aplicada através de um spray com a tinta aderente que se adequa a superfície do produto criando uma fina camada solidificada.

No desenvolvimento das peças do jogo, por possuírem uma estética basicamente cilíndrica, foi utilizado a tecnologia de usinagem em torno, através da madeira como matéria prima, pois nas quantidades as quais foram utilizadas se mantiveram em uma boa relação custo benefício para o projeto.

As mecânicas do jogo foram desenvolvidas utilizando uma análise de similares conforme mostra a tabela 1. Essa análise foi importante perante a comparação necessária do nosso projeto ao tradicional do xadrez. Pode se observar a semelhança e os pontos de evolução que diferenciam os dois jogos.

\begin{tabular}{|c|c|c|}
\hline & Mecânica de Movimento & Mecânica de Ataque \\
\hline Xadrez & $\begin{array}{c}\text { Por turnos, variando a } \\
\text { distância de movimento } \\
\text { baseado no tipo de peça. }\end{array}$ & $\begin{array}{l}\text { Através da finalização do } \\
\text { movimento da peça, em } \\
\text { frente a peça inimiga. }\end{array}$ \\
\hline War II & $\begin{array}{l}\text { Por turnos, através de } \\
\text { diversos tipos de } \\
\text { movimentos possíveis }\end{array}$ & $\begin{array}{c}\text { Através da rolagem de } \\
\text { dados para simular o } \\
\text { ataque e a defesa na } \\
\text { sorte. }\end{array}$ \\
\hline Damas & $\begin{array}{l}\text { Por turnos, variando a } \\
\text { distância pela quantidade } \\
\text { de casas disponíveis }\end{array}$ & $\begin{array}{l}\text { Através da finalização do } \\
\text { movimento da peça, em } \\
\text { frente ao inimigo. }\end{array}$ \\
\hline
\end{tabular}

\begin{tabular}{|c|c|c|}
\hline Go & $\begin{array}{c}\text { Por turnos, adicionando } \\
\text { peças ao tabuleiro sem } \\
\text { movimentação. }\end{array}$ & $\begin{array}{c}\text { Através do fechamento } \\
\text { de peças ao redor de um } \\
\text { grupo de peças inimigas. }\end{array}$ \\
\hline $\begin{array}{c}\text { Nosso } \\
\text { Projeto }\end{array}$ & $\begin{array}{c}\text { Por turnos, variando a } \\
\text { distância de alcance } \\
\text { dependendo o tipo de peça } \\
\text { e posição de altura no } \\
\text { tabuleiro. }\end{array}$ & $\begin{array}{c}\text { Através da finalização do } \\
\text { movimento em frente ao } \\
\text { inimigo, adicionando os } \\
\text { dados de ataque para } \\
\text { simular a sorte. }\end{array}$ \\
\hline
\end{tabular}

Tabela 01: Comparativo de mecanismos

A tabela 1 mostrou mecânicas de movimento e ataque, que foram testadas com protótipos físicos para simular e considerar as melhores soluções que combinassem a facilidade no entendimento das regras, a clareza das regras e a rejogabilidade que proporciona ao jogo (Marcelo e Pescuite, 2006).

Quanto aos resultados dos testes, indicam que o projeto físico está em conformidade com o briefing e a proposta, ou seja, pode ser encaminhado à sua produção final, investindo mais recursos para obtenção de itens de melhor qualidade, assim refinando o jogo.

O produto final precisa seguir os padrões de qualidade definidos na especificação da persona, indicado na fase de briefing. Na produção do protótipo final foram utilizados diferentes meios, conforme o custo e o método produtivo para cada peça do jogo.

Para realizar os testes finais, utilizamos um questionário aplicado aos jogadores, contendo questões específicas do jogo, a qual serviu como base para a releitura dos resultados finais do protótipo. Dentre as perguntas destacamos se possuía regras claras e de fácil entendimento na sua primeira partida, se a duração da partida era agradável e o nível de satisfação e divertimento.

Para os testes avaliativos do jogo, foi necessário a presença de 4 voluntários que foram submetidos a uma partida. Após uma explicação rápida das regras, foi iniciada a partida, e ao final os participantes responderam um questionário referente a algumas características que tornam um jogo válido - baseado nas informações de Marcelo e Pescuite (2009). 


\section{$16^{\circ}$ \\ ERGODESIGN USIHC CINAHPA}

Com base no feedback dos participantes do teste avaliativo, constatamos que o protótipo e as mecânicas desenvolvidas cumpriram sua função de entretenimento dos jogadores. Portanto, não houve fase de adaptação após a conclusão inicial do projeto. Os resultados apontam o êxito do projeto, perante os 04 participantes do teste, pois sua pontuação se estabeleceu com média de $94,8 \%$ nos índices de satisfação e qualidade, segundo as respostas dadas.

O detalhamento técnico do projeto é constituído das características técnicas das peças, a fim de possibilitar uma produção de escala industrial com a menor margem de erro possível. Os desenhos técnicos foram desenvolvidos utilizando o software SolidWorks, que possibilitou uma fidelidade à escala, dimensões e forma do produto.

O projeto possui três peças fundamentais para sua função prática como produto: (1) o tabuleiro, (2) o kit de peças e (3) os dados de ataque. As peças fabricadas, são de modo geral, essenciais para o conjunto do projeto - que constitui um kit de jogo para um jogador. Este conjunto é composto por 1 tabuleiro (utilizado individualmente por jogador), 3 dados de ataque, e as peças: 1 Marechal, 3 Generais, 3 Elites, 6 Artilharias.

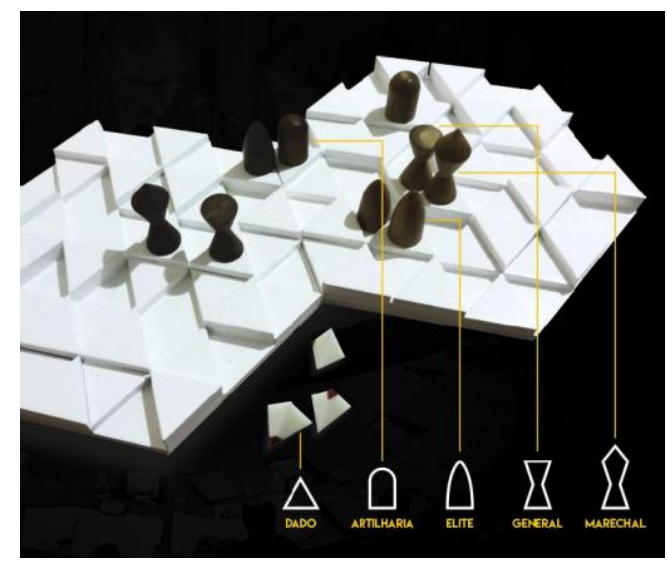

Figura 04: Peças do jogo

Da concepção estética do jogo, o visual das peças Elite e Artilharia, frente a temática de combate, remete ao formato da munição utilizada em armas de longo e curto alcance, de forma a tornar mais intuitivo a mecânica das peças. As peças Marechal $16^{\circ}$ Ergodesign - Congresso Internacional de Ergonomia e Usabilidade de Interfaces Humano Tecnológica: Produto, Informações Ambientes Construídos e Transporte

$16^{\circ}$ USIHC - Congresso Internacional de Ergonomia e Usabilidade de Interfaces Humano Computador

CINAHPA | 2017 - Congresso Internacional de Ambientes Hipermídia para Aprendizagem.

e General possui uma estética voltada ao ícone ampulheta, que simboliza o tempo e cria uma conexão direta com um dos recursos mais importantes no campo de batalha.

Uma característica que diferencia o jogo no modelo de peças é o sistema em que são separadas por jogador. No xadrez os usuários são divididos pelas peças de cores claras e escuras, totalizando assim duas possibilidades de jogadores apenas. Para o jogo proposto, devido a sua possibilidade de multijogadores, as peças devem ser vendidas em kits coloridos, onde cada kit contém uma cor, que será própria do jogador. Não se exclui a possibilidade de personalização das peças, o que aumenta ainda mais a fidelidade com o público nerd/geek.

Também realizamos um comparativo entre peças e funções dos jogos pesquisados e a proposta do nosso jogo, detalhados na tabela 02 .

\begin{tabular}{|c|c|c|}
\hline Xadrez & Nossa proposta & Função prática \\
\hline REI & MARECHAL & $\begin{array}{c}\text { Peça de extrema importância } \\
\text { estratégica possuindo movimentação } \\
\text { e ataque de curta distância com foco } \\
\text { em defesa pessoal. }\end{array}$ \\
\hline $\begin{array}{l}\text { DAMA } \\
\text { BISPO } \\
\text { TORRE }\end{array}$ & ELITE & $\begin{array}{l}\text { Peça de movimento de longo } \\
\text { alcance, importante no } \\
\text { deslocamento de peças no tabuleiro } \\
\text { e no ataque rápido a peças } \\
\text { estratégicas. Possui uma quantidade } \\
\text { reduzida para equilibrar a mecânica } \\
\text { e velocidade de jogo. }\end{array}$ \\
\hline PEÃO & ARTILHARIA & $\begin{array}{l}\text { Peça de movimento especial de } \\
\text { médio alcance, utilizada para variar } \\
\text { a estratégia de ataque e defesa } \\
\text { confundido o rival. }\end{array}$ \\
\hline- & GENERAL & $\begin{array}{c}\text { Peça de importância apenas } \\
\text { estratégia, pois tem relação direta } \\
\text { com os dados de ataque, mas pouco } \\
\text { poder de movimentação para ataque } \\
\text { próprio }\end{array}$ \\
\hline
\end{tabular}

Tabela 02: Comparativo de peças/funções

Da jogabilidade, o objetivo é eliminar o Marechal e/ou eliminar os três Generais, o que eliminaria os três dados de ataque do jogador, ocasionando a 


\section{$16^{\circ}$ \\ ERGODESIGN USIHC CINAHPA}

derrota na partida. Também é possível utilizar modos personalizados de jogo, como por exemplo, "o último homem", que consiste em um modo de jogo "mata, mata" onde o último jogador a permanecer com uma peça no tabuleiro ganha a partida. Também é possível os jogadores se organizarem em times, ou grupos, assim levando uma partida com vários jogadores a um nível mais elevado de estratégia e dificuldade.

Nos atributos destinados as peças, o Marechal é o mais importante para o jogo, pois se for capturado o jogo acaba. O General é responsável pela efetividade das investidas e ataques a outras peças através da mecânica de dados, cada um vai representar um dado usado na partida e sem ele não é possível continuar jogando. A Elite é responsável pelos ataques a distância pois possui um campo de ataque muito maior que as demais e a Artilharia é responsável pela defesa e ataques de menor distância pelo tamanho do seu campo de ataque.

A movimentação no tabuleiro (vide figura 05) é igual para todas as peças do jogo, variando apenas a quantidade de casas percorridas por cada uma.

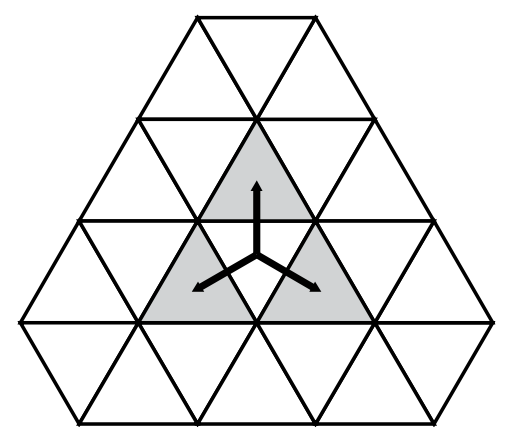

Figura 05: Movimentação tabuleiro

A quantidade de casas máximas a serem percorridas por uma peça variam de acordo com o tipo de peça e a altura da próxima casa que vai movimentar. Por exemplo, se a peça estiver em uma casa, e a próxima casa que deseja se movimentar for mais alta, a peça precisa subir no tabuleiro, o mesmo se aplica se a próxima casa for mais baixa, a peça precisa descer no tabuleiro. $\mathrm{Na}$ tabela 03 seguem as regras de movimentação por situação das casas próximas entre subida ou $16^{\circ}$ Ergodesign - Congresso Internacional de Ergonomia e Usabilidade de Interfaces Humano Tecnológica: Produto, Informações Ambientes Construídos e Transporte

$16^{\circ}$ USIHC - Congresso Internacional de Ergonomia e Usabilidade de Interfaces Humano Computador

CINAHPA | 2017 - Congresso Internacional de Ambientes Hipermídia para Aprendizagem.

descida da peça que deseja movimentar.

\begin{tabular}{|c|c|c|}
\hline PEÇA & DESCIDA & SUBIDA \\
\hline Marechal & $\boldsymbol{\nabla} 1$ & $\boldsymbol{\Delta} 1$ \\
\hline General & $\boldsymbol{\nabla} 1$ & $\boldsymbol{\Delta} 1$ \\
\hline Elite & $\boldsymbol{\nabla} 8$ & $\boldsymbol{\Delta} 4$ \\
\hline Artilharia & $\boldsymbol{\nabla} 4$ & $\mathbf{\Delta} 2$ \\
\hline
\end{tabular}

Tabela 03: Movimentação das peças

A regra é válida para a altura da próxima casa, não considerando a altura das demais casas nos níveis do tabuleiro. Nas casas que não houverem desnível, a regra para descida é válida.

A figura 06, exemplifica uma movimentação de uma peça Elite, com a primeira casa em descida.

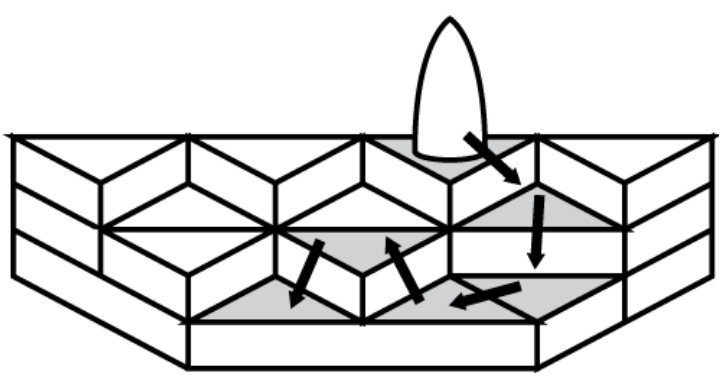

Figura 06: Movimentação da peça Elite (descida)

Como representado na figura 06 , não existem restrições quanto a direção do movimento da peça, o que dá maior liberdade ao jogador na elaboração da sua estratégia de jogo, além de deixa o jogo mais inovador, articulando a movimentação de acordo com a subida e descida das peças nos níveis do tabuleiro hexagonal.

\section{Considerações Finais}

O xadrez, utilizado como base no desenvolvimento do projeto, norteou os princípios de movimentação e ataque utilizados neste jogo. Tais princípios foram difundidos pelo próprio xadrez, tendo em vista sua vasta utilização nas escolas e também seu grande alcance como entretenimento, criando os padrões mentais necessários para a replicação em 


\section{$16^{\circ}$ \\ ERGODESIGN USIHC CINAHPA}

outros exemplares, como apresentado neste projeto.

Salientamos que durante o processo de concepção do projeto existiu uma linha de pensamento para transformá-lo em jogo digital, e inserir em escolas. Também buscamos proporcionar ao projeto uma linguagem direcionada para a geração Z .

A definição de persona (geração Z) foi uma etapa chave no projeto, pois auxiliou a modelagem do briefing e refinamento final, que buscou atender às expectativas destes usuários selecionados.

Através de uma pesquisa exploratória, buscamos em um primeiro momento, familiarizarmos com o tema proposto. A descoberta de novos conceitos sobre metodologia de jogos, especialmente jogos de tabuleiros, foram essenciais para o

desenvolvimento do projeto.

Sendo assim, obtivemos um jogo de tabuleiro construído e testado junto ao público, possuindo aprovação com índices superiores a 90\% nos critérios requeridos pela metodologia.

É importante deixar claro que o jogo está em fase de aprimoramento, e com isso, exige novos testes de jogabilidade e aceitabilidade, com um volume mais considerável de usuários. Somente diante destes novos resultados será possível vislumbrar do jogo físico para uma perspectiva de hipermídia que envolva uma prática pedagógica inserida nas escolas como aprendizagem ativa.

\section{BIBLIOGRAFIA}

ARRUDA, E. P. Fundamentos para o desenvolvimento de jogos digitais. [recurso eletrônico] Porto Alegre: Bookman, 2014.

CASTRO, C. Uma história cultural do xadrez. Cadernos de Teoria da Comunicação. 1994.

CHANDLER, H. M. Manual de Produção de Jogos Digitais. Bookman, 2009.

DOUBEK Josef. Xadrez para Principiantes. Editora Tecnoprint Ltda, 1982. $16^{\circ}$ Ergodesign - Congresso Internacional de Ergonomia e Usabilidade de Interfaces Humano Tecnológica: Produto, Informações Ambientes Construídos e Transporte

$16^{\circ}$ USIHC - Congresso Internacional de Ergonomia e Usabilidade de Interfaces Humano Computador

CINAHPA | 2017 - Congresso Internacional de Ambientes Hipermídia para Aprendizagem.

FIANI, R. Teoria dos Jogos. Elsevier. 2006.

LEITE, P. S. \& MENDONÇA. V. G. Diretrizes para Game Design de Jogos Educacionais. SBC - Proceedings of SBGames 2013. 2013

LOUREIRO Luiz. Xadrez. in Dacosta, Lamartine (ORG.). Atlas do Esporte no Brasil. Rio de Janeiro, 2006.

MANZANO, A. L., \& VILA, J. S. Iniciação ao

Xadrez. Artmed. 2002.

MARCELO, A., \& PESCUITE, J. Design de Jogos Fundamentos. Rio de janeiro: Brasport, 2009.

SALEN, K., ZIMMERMAN, E. Rules Of Play Game Design Fundamentals. The MIT Press, 2004.

SATO, A. K. Game Design e Prototipagem:

Conceitos e Aplicações ao Longo do Processo Projetual. IX SBGames - Florianópolis - SC, 8 a 10 de novembro de 2010. 